\title{
"Their accent is just too much": Racialized evaluation of voice in public radio production
}

\author{
Laura Garbes \\ laura_garbes@brown.edu \\ Brown University
}

\begin{abstract}
How does institutional racism shape who gets heard in the public sphere? In this article, I outline the institutional practices of racialized voice evaluation within the public radio production process. I find that institutionalized practices of finding sources and narrating stories have racially exclusionary impacts on whose voices make it onto public radio airwaves. Drawing on the experiences of 75 nonwhite employees in the public radio industry, I show that voices evaluated for broadcast are coded as nonwhite, their clarity and expertise are more likely to be questioned. For each institutionalized norm of voice evaluation, I identify strategies that these workers use to expand the voices that make it on air. These findings suggest that these evaluations place a burden on public radio employees of color that seek to deviate from these institutionalized norms. The research contributes to a growing literature on racialized evaluation by highlighting the role of the voice and sound in how institutional racism shapes cultural production. It also brings in the sociology of work to understand how racialized evaluation shapes the workplace experiences of employees of color in the cultural industries.
\end{abstract}

\section{Keywords}

Structural racism, cultural industries, radio, production analysis, sonic color line 


\section{INTRODUCTION}

People will still openly say, "We can't have that person on. Their accent is just too much." And then you go and listen, and you're like, "what are you talking about?" I understand everything they're saying. That happens so much. It's almost like I'm looking through a different prism at the world than a white person. That's where it gets spooky and weird because we're hearing the same thing and hearing it completely differently. - Arvand, public radio broadcaster and editor

How does institutional racism shape who gets heard in the public sphere? In the epigraph above, public radio employee Arvand experiences a mismatch in auditory perception with his white colleagues. He articulates how clear particular voice recordings from immigrants and communities of color sound, while his white colleagues interpret them as heavily accented, unclear and thus unfit for airtime. How does this dissonance between colleagues arise along racial lines? Why does this mismatch continue in an era when media organizations ostensibly want to encourage an outlook on the world more representative of changing American demographics?

The sociology of evaluation has unsettled assumptions of objectivity in evaluation standards, revealing instead the subjectivity of evaluative practices (Lamont 2012; Chong 2020; Velthuis 2005; Espeland and Sauder 2008), and evaluation's interconnectedness with the entire circuit of a cultural product (Childress 2017). There is a small growing literature on evaluation which shows that racism gets embedded in the consecration of cultural objects (Bledsoe 2021), the legitimation of cultural tastes (Gualtieri 2021), and the formation of entire cultural genres (Lena 2019).

I enter this conversation through a consideration of voice as an object of racialized evaluation. My site of study, the public radio industry in the United States, has an egalitarian mission to serve all Americans through both news-based and cultural programming. Despite this stated mission, its content has taken on particular popularity with the American professional class, who are treated as identifiable listener-members that form part of the public radio listening community (Mitchell 2005). There has also been a societal recognition of public radio's aesthetic (Loviglio 2013) and voice (McEnaney 2018; Chávez 2019); the iconic public radio voice has been indexed as mirroring the comforts and tastes of predominantly white, upper-middle class listenermembers (Kumanyika 2015). The mismatch defies recent efforts by the Corporation for Public Broadcasting, National Public Radio and other public radio distributors to become more accountable to marginalized communities (Corporation for Public Broadcasting 2019; National Public Radio 2020). By using this case I am able to ask: how are voices subjectively evaluated in a white racialized organization (Ray 2019; Garbes 2021)?

Further, critical research on organizations and occupations demonstrates the emotional and performative labor taken on by racialized employees to adapt to entrenched organizational norms (Puwar 2004), particularly black women (Wingfield 2010; Durr and Wingfield 2011). Yet there has been little conversation between this stream of research and the growing literature on racialized evaluation. By centering the perspectives of people of color in the public radio production process, my findings emphasize the material and psychic impacts that these racialized evaluation processes have on employees that resist institutional racism. 
The focus on employees of color in public radio and their experiences of voice evaluation within the production process reveals that institutionalized norms in finding sources and narrating stories have racially exclusionary impacts on whose voices make it to air. Drawing on the experiences of 75 nonwhite employees in the public radio industry, I show that voices evaluated for broadcast are coded as nonwhite, their clarity and expertise are more likely to be questioned. Further, I identify strategies that these workers use to circumvent the constraints of these racially exclusionary institutionalized norms.

By centering the auditory construction of race, my findings destabilize our assumptions about how we sense racial difference. In considering how racialized standards are constructed through the industry's valuation of voice, this paper demonstrates the role of the sonic color line in creating systemic inequalities in the cultural industry. Further, the research provides insight into the media's role in upholding the sonic color line through its perpetuation of an ideal standard language. The implications move beyond the cultural industries by showing that linguistic discrimination maintained through racialized evaluation practices embedded in seemingly nonracial processes.

\section{RACIALIZED EVALUATION PROCESSES IN THE CULTURAL ORGANIZATIONS}

The role of race and racism in producing and evaluating cultural products comes as no surprise, given the consistent work in racial theory across decades that demonstrates racism to be a structuring force in American life (Haney-López 1994; Omi and Winant 2014; Itzigsohn and Brown 2020; Robinson 2000). I attend to the processes of cultural production, as it moves us beyond the question of whether a cultural product is racialized, towards a better understanding of when and how cultural products are impacted by racism and race relations (Saha 2018).

Racism does not necessarily operate overtly within the cultural industries. Racially exclusionary norms are often invisible to the evaluators themselves (Bonilla-Silva 2007; Wang Yuen 2017). Understandings of race as a real social category have been made possible through the continual social practice of racism in American life, a structuring force so ubiquitous it has been rendered unremarkable. The social fact of race becomes real through what Fields and Fields (2014) call "racecraft": the practice of racism and the skillful disappearance of the act. When racist social practices persist over time, the outcome of racial inequality gets ascribed to racial difference itself rather than to the practice of racism that creates it.

It is this dual process of racecraft that makes the identification of racism within evaluative processes challenging. Recent work in the sociology of evaluation demonstrate that racism and sexism shape if and how cultural figures get consecrated (Bledsoe 2021), and how genres get legitimated (Phillips and Owens 2004; Lena 2019). Racialized evaluation extends to processes within organizations actively seeking to remedy Even as there is increasing racial representation across cultural industries in the United States, exclusionary ideological frameworks impact how workers of color and their stories are evaluated (Erigha 2020).

Further, the analysis of the experiences of nonwhite employees offers insight into how racialized organizations may shape and reify white dominant cultural narratives. Race is a structuring force in society's institutions, and racialized organizations constrain minoritized 
racial groups' agency while supporting and uplifting the norms associated with the dominant racial group (Ray 2019).

Within racialized organizations, workers of color perform a disproportionate level of emotional labor (Wang and Brewster 2019). Racialized emotions (Bonilla-Silva 2019) such as anger and frustration are coded as more acceptable and appropriate when white in the workplace (Wingfield 2010). This labor is often rendered invisible by colorblind ideologies and the myth of a post racial America (Evans 2013).

Yet some invisible labor can be integral to disrupting racialized institutional practices within organizations. These racialized social structures inform racial subjectivities (Itzigsohn \& Brown 2016), and one's perceptions of the world are shaped by one's social location in the racial order (Moreton-Robinson et al 2008). The position of nonwhite workers in a white racialized organization is a status of marginality that has the potential to produce a unique standpoint on racism and power, much like Hill-Collins theorizes about the standpoint of Afro-American women in society as "outsiders-within" (Hill-Collins 1986). Workers' racialized subjectivities may inform how they respond to workplace inequities; some workers of color produce counter narratives in their daily interactions as a form of microresistance to an industry's racial order (Evans and Moore 2015). How do nonwhite workers' racialized subjectivities impact how they perceive the production process within cultural industries? Further, how do these workers counteract dominant racialized evaluation practices?

\section{VOICE AS AN OBJECT OF RACIALIZED EVALUATION}

The human voice is subject to racecraft, just as visual phenotypic features like skin color and hair texture are (Stoever 2015; Karpf 2006). People infer class, race, and gender via a person's dialect (Lagos 2019; Robinson 2008; Bourdieu 1999), and there is a robust scholarship that points to how these inferences can lead to linguistic discrimination with material consequences. Inferring social categories via voice can shape one's (dis)advantage on the housing market, the job market, in healthcare access, or in classroom evaluations (Massey and Lundy 2001; Purnell et al 1999; Doss and Gross 1994). Existing studies are useful in tracking the outcome of linguistic discrimination.

By analyzing the voice as an object of racialized evaluation, the analysis of public radio production processes reveals the role of the Du Boisian sonic color line in the workplace. Adopted from W.E.B. Du Bois's prognosis of the color line being the greatest problem of the 20th century, sound studies scholar Jennifer Lynn Stoever (2016) has identified "the sonic color line" as an enduring, historically constructed mechanism that prevents white actors from hearing nonwhite voices in their full humanity. Stoever looks to Du Bois's Dusk of Dawn for this sonic metaphor for racialization: nonwhite people are in an unheard vacuum, trying to be heard in their case for justice and equality. They are subsequently separated from white people by a glass barrier, who do not even recognize the injustice to which those in an unheard vacuum are pointing:

It gradually penetrates the minds of the prisoners that the people passing do not hear; that some thick sheet of invisible but horribly tangible plate glass is between them and the world. They get excited; they talk louder; they gesticulate. Some of the passing world stop in curiosity; these gesticulations seem so pointless; they laugh and pass on. They still either 
do not hear at all, or hear but dimly, and even what they hear, they do not understand" (Du Bois, 1940: 131).

Arvand works within the public radio industry in the United States, which has an egalitarian mission to serve all Americans through both news-based and cultural programming. In this article, I focus on the production process within the public radio industry. I find that public radio's practices are shaped by the sonic color line, in ways that challenge the industry's mission to provide a public service over commercial profits. In the public radio production process, the sonic color line manifests as a systematic racialized evaluation of voices. When voices evaluated for broadcast are coded as nonwhite, their clarity and expertise are more likely to be questioned.

\section{THE AMERICAN PUBLIC RADIO INDUSTRY}

Before outlining the racialized evaluation of voice in story production, it is important to consider the context of the public radio industry, where this story production occurs. In the past forty years, there has been tremendous growth in public radio's prominence (Pew Research 2021). National Public Radio, in response to consistent threats of total government defunding, has embraced a path towards greater privatization and investment in marketing campaigns to sustain it (Pickard 2015). The Public Radio Exchange (PRX) and American Public Media (APM) have grown alongside NPR as competing distributors of programming to local stations. As the industry has grown into a recognizable market, its content has taken on particular popularity with the American professional class, who are treated as identifiable listener-members that form part of the public radio listening community (Loviglio 2008; Mitchell 2005; Chávez 2019).

Meanwhile, NPR's workforce has become steadily more racially diverse in the past 15 years, outperforming its commercial counterparts in employing a higher proportion of nonwhite employees (NPR 2021). While at first glance this may seem paradoxical, critical studies in organizational sociology have demonstrated that white norms entrench themselves in institutional culture over time and reinforce white dominance to the detriment of minoritized workforces. Such studies reveal that white norms are not necessarily incompatible with affirmative action plans, minority training programs, and other common efforts toward racial inclusion and diversity in a given field. The norms may, in fact, thrive in the presence of this organizational diversity work (Ward 2008; Berry 2015; Ray 2019; Puwar 2004).

The notion of public radio voice is biased towards an abstracted, idealized spoken language; while speakers and listeners think it conforms most closely to the written version of English, it is in practice a reflection of how the dominant group speaks (Hill 1998; Lippi-Green 2012). In the field of public radio, this is a white, well-educated social group that situates itself as civically minded and curious, something that historian Jason Loviglio refers to as the "NPR habitus" (Loviglio 2008). Public radio voice has become a well-known "type" of voice that ends up being a disciplining force in the production process. The voice of public radio in the $21^{\text {st }}$ century is most closely associated with the accent of white communities of the upper midwestern United States (Chávez 2019), but it is in fact more variable and received differently by different listeners. The voice of Ira Glass, with its nasality and once "odd" timbre, has shifted the auditory landscape of public radio in the $21^{\text {st }}$ century (McEnaney 2018). Some have pointed to NPR's early programming as path-breaking in its commitment to airing voices outside of the ordinary realm of authority at the time. There are famous instances of NPR broadcasters breaking from 
the mold of a traditionally authoritative male baritone voice, particularly women such as Susan Stamberg, a Jewish broadcaster who brought warmth and curiosity to a profession often limited to male authority (Loviglio 2008). In sum, descriptions of the public radio voice, just like descriptions of any speech community over time, are shifting, imprecise and elusive. With these differing accounts, it is difficult to empirically index public radio voice onto a stable set of linguistic conventions. Yet the widespread recognition of "public radio voice" consistently sets racialized standards that mark those heard as audibly nonwhite as not belonging.

Some reporters of color admit to feeling alienated by public radio's modal voice. Marta, a Middle Eastern reporter, admits she struggles to listen to her own station sometimes: "I don't know how to describe it, but it's like, when I listen to it, I force myself to do it, and it feels like they're talking to like, either young woke white people or old retired people." Academic and rapper A.D. Carson has quipped that he associates the sound of public radio with "middle-aged white dudes who sound like they just drank some really warm coffee" (Kumanyika 2015). Cultural critic Doreen St. Félix considers how, though voices associated with whiteness evoke particular associations, "white voice is an ideal that not even the white man can attain" (St. Félix 2018). In this way, voices associated with nonwhite communities are more consistently heard as nonstandard.

\section{METHODS}

Between January 3, 2020 and October 16, 2020, I interviewed 75 people of color currently working in the public radio industry in the United States. The findings in this article build upon these 75 qualitative interviews. I limited my sample to nonwhite employees, given that the focus of this paper is on where people of color experience racially exclusionary voice standards within the story production process. Of the 75 respondents, 22 identified as Black or African American; 21 identified as Asian or Asian American; 23 identified as Hispanic or Latinx; 4 identified as being of Middle Eastern descent; 5 identified as mixed race or biracial. I conducted in person interviews in January and February and conducted interviews over Zoom video conferencing from March until October due to COVID-19 travel and in-person meeting restrictions. Out of the 75 interviews, 70 fell within the range of 65-80 minutes; five interviews fell out of this range, the shortest lasting 45 minutes and the longest lasting 4 hours.

I recruited self-identified people of color that either previously worked or were currently working within the public radio industry. The interview sample includes employees and freelancers of the following: local-level public radio stations, National Public Radio, American Public Media, and Public Radio Exchange. The broadness of the recruitment sample inhibits me from making a claim about the policies of any particular station, organization, or network. However, the industry-wide approach is useful in understanding the norms dominant across the entire field.

From the point of initial recruitment via audio conferences and email recruitment, I proceeded using snowball sampling. At the end of each interview, I asked respondents to share this call for interviews with other people of color in the public radio industry who might be willing to participate. My own position in the field as a woman of color embedded within an elite, white dominant space provided an opportunity to build rapport more easily with initial interviewees. Respondents sometimes cited that they were initially hesitant to speak with me 
when I sent out interview requests, but that they were reassured by colleagues that had already spoken with me.

Each interview followed a semi-structured interview script, which I designed to focus on employees' workplace experiences. In this article, I consider respondents' discussions of workplace production processes. The focus on production from the perspective of cultural workers revealed the logics that drive creative work in the industry (Saha 2013; Hesmondhalgh and Baker 2010; Negus 1999). It also offered possibilities to see where cultural workers' own subjectivities shaped their responses to such logics (Saha 2018).

All 75 interviews were transcribed using Descript, with assistance from a freelance transcriptionist who cleaned up 50 of the automated transcripts I coded the interviews using NVIVO 12 qualitative analysis software. In coding the interviews, I identified common points of discomfort with the dominant norms of the industry, as well as their reactions to these moments of discomfort. Further, in their explanations of the radio pieces they were most proud of, I coded the conditions that made the successful production of these stories possible. The quotes below are anonymized, attributed to respondents' chosen pseudonyms.

\section{RESULTS}

Many of the respondents I spoke to, regardless of their own ability to conform to a "standard" public radio perspective and voice associated with the white professional class, experienced moments when the racialization of voice standards were made clear to them. There are two main points in the production process when my respondents encountered the exclusion of nonstandard voices associated with nonwhite communities: in sourcing and voicing. When sourcing stories, editors put extra scrutiny on guests without media training and with nonwhite "foreign" accents. When voicing stories, broadcasters who speak in nonstandard English encounter pushback from audience members and editors who question their fitness to be on air. As I will outline in the results, these designations of nonstandard are racialized- with European "foreign" accents bringing less pushback than "foreign" accents from the Global South. For each institutional practice of racialized voice evaluation, employees of color within my sample have found strategies to diversify the range of voices and accents on air. However, these strategies put a disproportionate burden onto the individuals looking to deviate from public radio industry's institutional norms.

\section{Racialized voice evaluation of sources}

When a story pitch is approved for production, the producer or reporter must line up sources to speak on air. There has long been a widespread bias towards white male sources in broadcast journalism (Zeldes et al 2012; Poindexter et al 2003), and sourcing practices in the public radio industry are no exception. National Public Radio conducts a yearly audit on the organization's weekday newsmagazine programs. In FY2018, the voices on air were " $83 \%$ white and 33\% female." While the organization has made a concerted effort to improve these statistics, the bias persists. As one respondent within the national organization recalled, "There was a brouhaha at NPR [in spring 2020] in which one of the weekend shows, for an entire hour, every voice on it was a white dude. How does that even happen? You have to try." 
This bias towards white male experts holds across the public radio industry, and it has been documented through self-audits in local stations like WHYY (Wenzel 2020). There have been attempts to improve these statistics by encouraging employees to track their own sources ${ }^{2}$ as a way to promote accountability and self-reflexivity in their own practices. Respondents at other local stations noted the effectiveness of source tracking in reducing the bias towards white male experts. Erin, an Asian American reporter, noted, "forcing yourself to audit your sources that definitely makes me feel I should work harder to get more diverse sources."

Still, there is a sonic dimension to sourcing that is not captured through this demographic tracking process: a public radio guest or interviewee still needs to be a "good talker." This phrase came up in 12 interviews and so I began to ask remaining respondents how they defined it. The majority of those interviewed defined "good talker" through two features that made a person's voice "easy to understand." First, those labeled as "easy to understand" were more comfortable with media interviews. This level of media savvy is more often associated with people in the professional class, i.e., in white collar professions. Second, people who are labeled as "easy to understand" often have "standard" American accents commonly understood by editors and by the perceived audience. This preference disproportionately excludes those with foreign, often nonwhite, accents. Taken together, these features of a "good talker" maintain white, upper-middle class dominance in the evaluation of a source's voice.

Good talkers are often people that belong to the white professional class. As one Black reporter Sammy pointed out, "a good talker can toe the line between being a friend and an academic." In other words, the ideal good talker brings expert level analysis, and is relaxed while doing so. Darren, a Black broadcaster, summed it up this way: "when they mean 'good talker' they always mean somebody who works at fucking think tanks. You end up with the same institutional white voices." The key part of Darren's claim is that they are not simply white voices: they are voices that come from white dominant institutions. This conception of good talker often prioritizes professional expertise over lived experiences. Angela, a Black reporter, told me she associates this practice with public radio:

I grew up listening to NPR and it would be like, "There's a famine. Oh no." And they would talk to someone who was starving. And then they'd be like, "Let's talk to this expert from Oxford." What if you talk to people in the country?

This standard becomes clear when we trace the path for sources that do not hew to these expectations. For instance, Grace, a producer of color, received negative feedback for bringing on a less experienced guest to the show:

We looked for the voice of a protestor, and we brought this [Black] guy on, and he was not ... He wasn't a professor, you know? He hasn't been trained in how to speak to media. He had really interesting things to say. He was just like a little bit more clunky when it came to saying them. And [the host] was unhappy with him. But my team was like, "No, he's really good." Like, just because someone isn't a great talker doesn't mean they don't have something great to say.

In this example, the host was frustrated by a guest that was not as ready for a live, freeflowing discussion. The burden goes onto the guest to be a good talker, instead of the interviewer 
adjusting her questions to connect with the guest, or the station providing media training for the protestor.

Further, clunkiness or reticence on air, while associated with inexperience or not being a "good talker," can actually enhance the emotional resonance of a story. Esteban, a Latinx reporter, explained to me how sometimes discomfort or lack of smoothness on air can be useful in setting the scene of a story. For instance,

One of my sources was a [Latino] guy who was very shy, had never been on radio before, but he had this beautiful story [about how he turned to music to learn to communicate with his family].. the hesitance and reluctance in his voice in and of itself is part of why he is that way.

In both these examples, Grace and Esteban managed to get sources without media training on air. However, bringing these voices on air brought more labor for these employees. Grace had to defend bringing on the protestor as a guest; Esteban had to do a more extensive edit of the piece. The extra work is not compensated, and often not even recognized. A Middle Eastern reporter, Cynthia, said, exasperatedly of all the extra unpaid work she had to do, "It's so much more work. No wonder it's all white! I get paid too little [to do this extra work]."

Respondents noted how their editors put extra scrutiny on guests or features from immigrant or low-income communities of color. Reporters struggled to get sources with Chinese accents on air, for example, even if the source's perspective was highly salient. One reporter often heard that "you have to be able to understand [the accents] while you're driving down a highway or on your morning commute." The "you" presumably belonged to the imagined white, upperclass public radio listener.

Producers and reporters of color cited clips of sources who were unintelligible to white editors, but whom they could understand without strain. Arvand, a Middle Eastern broadcaster cited in the introduction, described this phenomenon at length:

It's always a white person that's standing on the other side being like, 'We can't book this person because I don't understand them.' Well, we [people of color on the team] all understand them. Maybe because I have parents who have really heavy accents of English. Maybe that's it. But no. I got Black colleagues who didn't grow up with that heavy accent, because I don't consider any Black folks I know to have the accent my parents do. My parents literally speak broken English. But even my Black colleagues heard it the way I did.

Though in some instances this is chalked up to the need for clarity on air, the different reactions to different accents reveals racialized notions of clarity, as in these two examples from a Black international reporter, Mara, on African accents versus Italian accents:

We were covering stories in Sudan, and editors would be like, "Oh, that audio's unclear." And I was like, "These are the only people who have internet access. You can definitely hear what they're saying... The audio is fine." And, and they were like, "OK well their accent is like ... Their accent is really hard to understand." 
The contrast to that for me was the Italian soccer team when... they did this whole speech. And everyone was like, "That's beautiful. Let's play the speech in Italian for a really long time." And these were the managers who were usually like, "I can't understand this like Japanese language.. It's not clear to me." Or like, 'It's just bad connection,' when it wouldn't be a bad connection.

Another Black producer, Karla, noted the same phenomenon, which she called a "hierarchy on certain accents":

Just the other day I produced a story with this Congolese [content expert]... I could understand everything he was saying... I had an editor who had told me, "Oh, come on, his accent is so thick. And I'm like, "Really? I understood everything he said." I asked a few of my friends afterward, [and they could all understand it].

I've also produced interviews with this French academic who had a heavy French accent. But you know, this guy's French and he has a French name. And... that's never a problem.

Both employees saw a gap in how European accents were evaluated in a more favorable light than African accents. This racialized valuation of accents can inhibit valuable sources from getting on air. The best possible option for a radio piece, according to a number of employees I spoke to, is to use people's original voices as much as possible. However, when conducting interviews in English with people who have thick accents, even when these people speak proficiently, there is a risk that the editor will reject the original interview due to lack of clarity. Amelia, a Latinx reporter, internalized editors' reactions to previous interviews she had done in English, and conducted her subsequent interviews in Spanish:

I even started policing myself in that sense ... There were definitely times that I was like, 'I understand this person fine, but like, they have an accent as thick as my mother which I don't think my editor Bob would actually like.' I imagined him saying, 'They're tough to understand, we shouldn't include this.'

Amelia, in response to her editor's previous comments, conducted the interviews in Spanish and translated it into English. This shift causes more work for Amelia, without additional compensation. At the same time, conducting the interview in Spanish further excludes nonstandard English foreign accents. When station employees anticipate these reactions, they may restrict the range of accents to increase the probability of their recordings being approved.

Overall, the industry's unspoken definition of "good talkers" is a manifestation of the sonic color line in contemporary story production. The preference for speakers that are comfortable onair leads to a higher use of experts from white-dominant institutions; the preference for "commonly understood" accents reflects the perceptions of both editors and audience members, disproportionately excluding foreign accents. Further, employees of color noted that foreign accents associated with white ethnic groups, such as Italian and French accents, were reviewed more positively than accents of Congolese and Sudanese sources. In filtering out non-white voices through the racialized evaluation of sources, the industry produces content that reinforces existing voice standards associated with whiteness. 


\section{Strategies for more inclusive sourcing}

Within the public radio industry, some of my respondents pushed to broaden the conception of "good talker" in two different acts of micro resistance: (a) spending more time preparing and editing sources; and (b) conducting interviews in foreign languages with an English translation. These strategies open up space for a wider diversity of sources while still producing work that reaches the standards of the industry.

Some respondents agreed that if guests, sources, or experts are not used to speaking into a microphone, they are less likely to be "good talkers." Several reporters insisted that this woodenness is avoidable through preparation and patience:

It's not really about being a bad talker. It's about making people comfortable, helping them to explain things and I think that, when we look at diversity, it's like, certain interviewers work to make people comfortable... which makes for better talking.

Another producer, Michelle, noted that these the clarity of English language learners on air: "Let's actually listen to people and what they're saying and what they're trying to say and come back to them. 'Is this what you mean? Did I understand you correctly?' One Black editor, Jane, had a mentor that guided her through how to prepare guests on a live show. She recognized that "good talkers" are made, not found, but that it is not a typical part of a reporter's training to elicit "good talk":

Sometimes when I hear someone bomb on a live show, it's like I wonder how they were prepped. Did they understand the parameters?... I don't think that producers are trained... on the responsibility that they have to prep guests and that, they like, make the show in that way.

In addition, some respondents expressed frustration at white editors being quick to dismiss voices as incomprehensible, even if they add to the story. Michelle developed a list of editing techniques she would use to help make the accent "work":

I would often bring back tape and I said I'd spoke to an Asian American man. He has an accent. I say, 'Maybe we can present it this way.' Instead, you would get, 'this person isn't going to be comprehensible'; or 'how much Spanish are you going to put on the air?'; or 'People will tune out when they hear Spanish or whatever the language is.' I say, 'No, no, no. We can put it on and then we can summarize.'

Both examples above showcase that the voice standards in broadcasting can be shifted to ensure clear enunciation and speech that is interesting and dynamic, without excluding guests without the training and experience within dominant institutional spaces. However, producers, reporters and editors are not systematically taught to guide their guests on how to ensure their voices come through clearly and compellingly on air.

Further, journalists can diversify the sources and voices eligible for broadcast by conducting interviews in foreign languages and translating them. However, newsrooms often 
undervalue the labor of translation work by their multilingual employees. Deirdre, a multilingual reporter of color, walked me through the added labor that goes into this process:

Let's say I conduct an interview in Spanish. It's an hour long interview in Spanish. Now, I have to transcribe that interview from Spanish [audio] to [written] Spanish and then from Spanish to English. And then I have to pull the important parts in English into a separate document to then organize it into a story. So, even in the production of that story, you're adding two extra steps. You have to really be committed to wanting to do it because otherwise it's not worth the time.

When I asked Deirdre whether this labor is compensated, she explained that most of this labor remains in the background, invisible to her editor:

[My editor] doesn't recognize the amount of work that I'm doing on the back end... I resorted to having to pay somebody [online] to transcribe my Spanish stories into Spanish ... And then I can just transcribe whatever I want into English, but then I need [help from colleagues or friends] sometimes because I wanna make sure that I got the translation exactly right.

Sometimes, bilingual producers of color must do this translation and interpretation work for [mostly white] monolingual English-speaking reporters. A bilingual Latinx producer, Javier, expressed frustration at being used as a translator to help report immigration stories, when he is trying to build his own portfolio of immigration stories as a freelancer on top of his producer position:

As one of the only Spanish speakers at my station, I have been thrust into this role of interpreting and translating for reporters who are doing immigration work. I'm not compensated for it. It just gets exhausting doing this work for reporters who are very talented, who I adore, and admire as colleagues of course, but who kind of rely on our labor to translate and listen to the interpretations so that they can get the story right... that takes away time you could be doing your own story on immigration stuff.

These examples point to a racialized double standard of which linguistic competencies hold enough social currency in the American radio context. Translation and interpretation work remain undercompensated and undervalued as a journalistic credential, even when the work is necessary for producing a story about a non-English speaking community. While the practice allows for a broader range of sources, it increases the labor for translators and interpreters withoutrecognition of this additional work.

\section{Racialized voice evaluation of reporters and hosts}

Public conceptions of public radio voice impact the way that reporters and broadcasters construct and maintain a voice to report and narrate their stories. Media studies scholar Christopher Chávez finds that NPR, in cultivating a unique voice "meant to distinguish the network in a competitive media marketplace" (2019: 15), has limited the range of performances for Latinx people on air. When Rutgers University professor and radio producer Chenjerai Kumanyika published a manifesto on the whiteness of public radio, he noted his own 
experiences as a Black man feeling the need to conform and alter his voice to one registered as more consistent with ways of speaking associated with the white-dominant professional class. Respondents in my sample picked up on similar cues, often through subtle instruction of whose voices are prominent in the industry, particularly through journalism schools and other training programs:

Especially when you're in school, the way they teach it to you is that you're supposed to mimic the art form, as opposed to create your own or reinvent the wheel. When I was listening to it, I thought, I have to be like that person. I don't think that every single piece a professor would bring in was a particular NPR white voice-I remember I would hear a lot of Ailsa Chang's pieces - but obviously there aren't a lot of people of color on the radio.

This pattern of whose voices are heard most often signals the existing style of public radio, making it more difficult to break out of that norm. Respondents are aware of the dominant cultural form and a pressure to conform by unspoken modeling. Contemporary unspoken linguistic norms of the public radio industry are circulated through a consistent pattern of white dominant voicing in existing public radio stories. They are then managed through audience and editor reactions to voices that deviate from the existing content.

Several broadcasters noted that the negative feedback sticks with them. For instance, a Black reporter Aubrey read a comment that her intelligence was being questioned because of the way she misspoke on air one day, when she said "cain't" instead of "can't." Citing the fact that she was employed in the public radio industry, the commenter said, "I assume you're smart enough to get this."

The commenter still understood the content of the piece, and he knew that "cain't" was a variation on "can't." His chastisement clearly connected intelligence to the ability to speak a standard English associated with the white professional class. Aubrey reflects that the comment "was not taking my intelligence as a given. It was making my intelligence a question, like, 'I guess you're smart enough to [work in public radio].' You do take it on a bit."

A Latinx broadcaster, KK, told me about a listener calling in to chastise her for mispronouncing the word "potent." He shamed her for dropping the middle t, pronouncing the adjective as "po'ent." Reflecting on this, she said, "it was a person saying how disappointed they were that I'm allowed to be on the radio when I can't say things, when I can't pronounce things correctly, and that I should be a role model and I should feel ashamed of myself for not being able to pronounce things correctly." Again, using "po'ent" as a variation of "potent" did not detract from the listener's understanding.

Why did these pronunciations of "cain't" and "potent" elicit such outsized reactions from audience members? These broadcasters' voices, in these utterances, do not match the audience's expectations of public radio. Jonathan Kern (2008) writes in the popular NPR guide to "sound" reporting to make sure audio reporters rehearse the script to speak in "a way their mothers could understand." Following this advice is rewarded when raised in a white-dominant cultural field with upper-class white mothers, but such advice is fraught for some non-white radio professionals whose identity is not reflective of the normative professional field of NPR. 
As Aubrey explains, "I talk the way my mom talks, my grandparents, the people around me talk this way. So [the commenter] is saying this about all these other people who talk just like me who are very intelligent." The audience feedback indicates that these reporters using words familiar to them and their communities, like cain't and po'ent, do not live up to expectations set by the standard language ideology of public radio voice. This mismatch indicates an implicit assumption of the race and class upbringing of public radio professionals that would be voicing stories. If your voice does not conform to listener expectations of a public radio broadcaster, your intelligence and authority may sometimes be questioned.

Another audience reaction is surprise when the voice they hear is deemed appropriate, yet they assume that the broadcaster's race is white. NPR host of All Things Considered, Audie Cornish, is a Black American woman who says many listeners get confused when they meet her, because her accent is associated with upper middle-class white America (Nigatu and Clayton 2015). Many other respondents noticed a similar surprise on the faces of both sources and listeners that meet them in person. Jessica a Black reporter, made it clear that nonblack audiences, particularly white people, were the people that seemed to have the strongest reactions:

I am the NPR voice. I fucking embody it. And so it flips people out when they meet me. 'Well, you don't sound, you know, South, so Southern' and I'm like 'South what?' I mean, yes. Black folks sound all kinds of ways. There are as many ways to be and sound Black anywhere as there are to be Black. And the only people who don't get this are white people. Black people are completely fine with it.

Ultimately the expectations of public radio voice bring career advancement for people of color who are more able to conform to the linguistic expectations associated with public radio. Many respondents who noted their voices could be coded as white were people of color raised in middle to upper-middle class white suburbs, or with some access to elite education, or both. Several respondents felt ambivalent about their voices offering them professional advancement. Evan, a Latinx reporter, pointed out his own privilege at being seen as bringing diversity but not making white people uncomfortable: "I don't think that I've ever been offensive to white people... I have no doubts that a big part of the reason I have gotten to where I have in my career is because of the way I sound."

However, if your voice is accepted, it may serve as a rationale to exclude non-white voices that do not conform to the public radio standard. Jessica notes that while embodying the NPR voice, she remains vigilant about the treatment of her voice impacts fellow women of color in the industry. She recalls how painful it was to realize that a fellow Black reporter, Cassandra, was instructed to sound like Jessica.

I have tried to do my best to support people who do not sound like me. We [in the public radio industry] seem to have a problem allowing any accents except British accents to be on the air. So it's just a problem. People have somebody with a Latino accent, somebody with an accent from Asia, it's just, it's really hard for people [in the public radio industry] to accept.

Further, if you do conform to listener expectations, your racial authenticity may be questioned by audiences and colleagues. When Latif, an Asian American reporter, was co- 
reporting on a community of color with his Black colleague, listeners questioned their ability to report on nonwhite communities: "Someone was like, 'You got these two white reporters... How dare you guys talk about this,' and it was this crazy thing. We're both immigrants, we're both people of color. It was an outlier, but it stuck with me because it was so weird. We sound like ourselves."

Public radio employees of color systematically face a toll in navigating on-air performance: either conform to a standardized language associated with whiteness or to voice diversity through performance. Either way, they are made to consider their own racial difference in the workplace and adjust to conform to the tastes of white upper-middle class audiences.

When reporters born outside of the United States with non-American accents voice stories, editors often fear that the audience will not understand them at all; at times they resolve this fear by keeping such accents off the air altogether, reallocating voicing opportunities to American born speakers. A Latinx reporter Sabrina recalls an experience where a Chinese intern, who broke a news story, was not able to present it on account of her accent:

Her English was good. It did sound like it was her second language, but you could understand every word that she's saying without any strain. And she reported this story that was on the front page of the morning newspaper in town. She produced a radio version of that story. The editor wanted this white man to re-track her voice because she had an accent. And I said, 'There's no need. I'll coach her. I'll make sure that she sounds clear and that her intonations are good.' And so I worked, we both stayed late that day to get her stories tracked and it sounded great. But then the next morning when the story, five minutes before the story aired, I found out that the white guy had re-tracked her story that morning.

Supervisors in this example denied this Chinese reporter the opportunity to voice their own piece. This denial is a hindrance to professional development in an industry where on-air presentation, as I heard from over ten interviewees without prompting, "makes you more indispensable."

Another producer witnessed the denial of airtime to multilingual reporters whose first language was not English. While their linguistic credentials were necessary to report the story, they were never able to voice those same stories on account of their accents:

There's so many people who are doing translation work 'cause they know Russian, they know French, they know Farsi, they know all these things, and we can't put them on the radio? I know this one reporter, she does have an accent, but she is a reporter, and they would say, 'I can't understand her well so she shouldn't be on the radio. She can file written reports.' And I was thinking, 'You sent her to Saudi Arabia. She has been interviewing people in ISIS, and she can't be on the radio? You've endangered this woman for months, and like now you say you can't understand her. Why did you hire her?'

Taken together, the typical voicing process reveals the sonic color line at work in the public radio industry. The examples above demonstrate a systematic preference for voices associated with the white professional class, who are seen by the audience as intelligent, clear, and trustworthy.

Audience members chastise broadcasters and reporters that fall outside these standards, especially if they use nonstandard English associated with communities of color. Editors are hesitant to put 
non-American accents on air, curtailing opportunities for these reporters. In filtering out non-white broadcasters and reporters through the racialized evaluation of their voices by both audience members and editors, the industry produces content that reinforces existing voice standards associated with whiteness.

\section{Strategies for more inclusive voicing}

Within the public radio industry, some of my respondents pushed to broaden the conception of "public radio voice" in two different acts of micro resistance: (a) internalizing different voice models; and (b) explicitly mentoring reporters and broadcasters to break away from dominant conventions. These strategies place the onus on individual broadcasters, reporters and supervisors to recognize and actively reject dominant, unspoken voice expectations.

People cited listening to Sam Sanders, Shankar Vedantam, and Ayesha Rascoe and feeling encouraged to sound "less like the typical white voice." Some respondents discussed a very intentional shift away from conformity to public radio voice. D.B., a Black reporter, started out by trying to sound the way a "public radio person" would. However, she said that in the past two years, she has allowed her own accent to show through:

It was partial[ly] just confidence in myself and also hearing Ayesha Rascoe [a Black woman widely perceived to have an audibly Black southern accent] on air. She sounds very distinct in her voice. She felt like somebody I would just meet hanging out with friends. That made me feel a little bit more confident in embracing my voice and my voice being authentic to who I am.

Other respondents cited examples of other voices on public radio giving them the courage to make reject conformity to public radio voice. An Asian American reporter, Derek, remarked how meaningful it was to hear a Latinx reporter use Spanish-language pronunciations:

I was always amazed the way that other journalists of color were able to show their racial identity and be unapologetic for it and say this is why I am. I remember at a certain time, there's a listener who actually criticized Sarah Gonzalez because of the way she said Spanish names in her stories. She was like, 'Look, as a Latina, this is the way I always say that. That's the way I speak. If you don't like that, then that's your problem.' I was like, that's great.

Derek went on to talk about how this use of Spanish-language pronunciations increased his comfort in saying Chinese place names properly:

That really inspires me in some ways because when I say Chinese [proper nouns], then I'll say it in Chinese [pronunciation]. I don't really know what that means for the listeners. I hope that it shows that there are people in media who are proud of our culture and our language and want to make sure that's represented. That's really important to me. During this whole coronavirus thing, I wouldn't say "Wuhan" [American pronunciation]. I would say "Wuhan" [Chinese pronunciation]. I wouldn't say "Hubei" [American pronunciation]. I would say "Hubei" [Chinese pronunciation]. 
The reporters above actively worked to shift their own relationship with their on-air voice. This strategy hearkens back to Kumanyika's vocal color manifesto, where he re-records his voice three times to "sound like himself" rather than an imitation of what he thinks he is supposed to sound like. Reporters citing non-white voices as models for possibility, while powerful, points to the work they must do to reclaim their own voices in the space. As a South Asian producer, Noha, quickly reiterated after noting these exceptions, "still.. for the most part, it's a really, really white space." Individuals pushing back against voice standards recognized that they were doing so within a structure that more often rewarded one's conformity to the existing standards.

While some employees internalize these deviations from the norm as their new standard, leadership that encourages this type of thinking has a significant impact on how broadcasters and reporters feel about their own voice. One Latinx reporter, José, once self-conscious about trying to imitate his white colleagues, pointed to the difference that guidance from management makes:

The last couple of years I've really been encouraged as to sound myself. That's what folks want which is a really nice start, as far as inclusion and making people feel welcome. reporters:

A Black managing editor discussed her willingness to take a stand on behalf of her

This one reporter... There are some words that she might say that you might go, 'what did she say?'; but for the most part, she's really solid as a reporter and finds the kinds of stories that I would just love to hear more of. But when she does stories covering schools, this one person would say 'I can't even understand what she's saying and why didn't she talk right, blah, blah, blah.' He's done it a few times. The first time he called, I tried to call him back but couldn't [trace the number]. But after that when he called, I would say to him, 'If you're a member, you're not the kind I want, I don't want your money.'

This management-level support for voices that deviate from the unspoken standard is a welcome change for their employees. However, this support is contingent on the discretion of individual managers actively resisting the feedback of frequent listeners. The strategy is therefore limited in its scalability and places the burden on individual managers rather reprioritizing feedback in the industry more broadly.

The expansion of potential role models and the intentional mentorship and guidance to reject any preconceived notions help to slowly shift the boundaries of public radio voice. However, these acts of micro-resistance are not adequate substitutes for a broader industry-wide shift away from the systematic privileging of white upper-middle class ways of speaking.

\section{CONCLUSION}

In this article, I considered how institutional racism shapes who gets heard in the public sphere. I took the case of public radio production as my research site, given its stated commitment to serving America in all its diversity. Specifically, I asked: how are voices subjectively evaluated in a white racialized organization? 
I interviewed 75 nonwhite public radio employees to analyze the production process from an "outsider-within" perspective. In both sourcing and voicing stories in public radio, respondents reported a systematic racialized evaluation of voices, which disproportionately excluded nonstandard accents associated with nonwhite communities. In sourcing stories, editors put extra scrutiny on guests and interviewees who have non-standard accents or who are not comfortable on air. In voicing stories, broadcasters who speak in non- standard English encounter pushback from audience members and some editors who question their fitness to be on air. These exclusions uphold the dominance and centrality of white, upper-middle class voices.

These exclusionary practices within public radio production process reveal that some professional fields operate within an economy of racialized emotions. This economy favors particular white and upper-middle class sensibilities. The systematic devaluation of nonwhite voices upholds public radio stations as white racialized organizations, placing a disproportionate burden on public radio employees of color that seek to deviate from these these racialized voice evaluation practices.

My findings also show that in the sourcing and voicing of public radio stories, some respondents developed ways to work around or push back against the constraints that these voice evaluation practices posed. To include more sources, some employees of color expanded source lists, prepared guests and interviewees, and edited clips for clarity. In working to redefine what a public radio employee "should" sound like on air, some employees used voice role models that have become prominent to bolster their own construction of a voice they are comfortable with. While it might be tempting to see these acts of micro-resistance as pointing the way forward, it is important to consider the disproportionate labor placed on employees of color in these actions.

This research is consistent with other recent studies from the production of culture perspective that ask how racemaking happens within the black box of production (Saha 2018; Saha 2013; Erigha 2020; Wang Yuen 2017). By centering the auditory construction of race, my findings destabilize our assumptions about how we sense racial difference. In considering how racialized standards are constructed through the industry's valuation of voice, this paper demonstrates the role of the sonic color line in creating systemic inequalities in the cultural industry. Further, the research provides insight into the media's role in upholding the sonic color line through its perpetuation of an ideal standard language. The implications move beyond the cultural industries by showing that linguistic discrimination maintained through racialized evaluation practices embedded in seemingly non-racial processes. 


\section{REFERENCES:}

Berrey, Ellen. 2015. The Enigma of Diversity: The Language of Race and the Limits of Racial Justice. University of Chicago Press.

Bledsoe, Ashlee. 2021. "Walk the (Gendered and Racialized) Line: Retrospective Consecration and the Rock and Roll Hall of Fame." American Behavioral Scientist 65(1):59-82. doi: $10.1177 / 0002764220959686$.

Bonilla-Silva, Eduardo. 2013. Racism without Racists: Color-Blind Racism and the Persistence of Racial Inequality in America. Fourth edition. Lanham: Rowman \& Littlefield Publishers.

Bonilla-Silva, Eduardo. 2019. "Feeling Race: Theorizing the Racial Economy of Emotions." American Sociological Review 84(1):1-25. doi: 10.1177/0003122418816958.

Bourdieu, Pierre. 1999. Language and Symbolic Power. 7th ed. Edition. edited by J. Thompson. Cambridge: Harvard University Press.

Brunsma, David L., Nathaniel G. Chapman, Joong Won Kim, J. Slade Lellock, Megan Underhill, Erik T. Withers, and Jennifer Padilla Wyse. 2020. "The Culture of White Space: On The Racialized Production of Meaning, The Culture of White Space: On The Racialized Production of Meaning." American Behavioral Scientist 0002764220975081. doi: $10.1177 / 0002764220975081$.

Chávez, Christopher A. 2019. "Whose Is the Voice of the American Public? Latinx Speech and the Standard Language Ideology of Public Radio." Communication and Critical/Cultural Studies 16(4):308-25. doi: 10.1080/14791420.2019.1665194.

Childress, Clayton. 2017. Under the Cover: The Creation, Production, and Reception of a Novel. Illustrated edition. Princeton: Princeton University Press.

Chong, Phillipa K. 2020. Inside the Critics' Circle: Book Reviewing in Uncertain Times. Princeton, NJ: Princeton University Press.

Corporation for Public Broadcasting. 2016. "Other Reports.” Retrieved August 27, 2021 (https://www.cpb.org/aboutcpb/other-reports).

Doss, Richard C., and Alan M. Gross. 1994. "The Effects of Black English and Code-Switching on Intraracial Perceptions." Journal of Black Psychology 20(3):282-93. doi: $10.1177 / 00957984940203003$.

Douglas, Susan J. (Susan Jeanne). 2004. Listening in: Radio and the American Imagination.

Du Bois, W. E. B. 2011. Dusk of Dawn: An Essay Toward an Autobiography of a Race Concept. Transaction Publishers. 
Durr, Marlese, and Adia M. Harvey Wingfield. 2011. "Keep Your 'N' in Check: African American Women and the Interactive Effects of Etiquette and Emotional Labor." Critical Sociology 37(5):557-71. doi: 10.1177/0896920510380074.

Erigha, Maryann. n.d. "Racial Valuation: Cultural Gatekeepers, Race, Risk, and Institutional Expectations of Success and Failure." Social Problems. doi: 10.1093/socpro/spaa006.

Evans, Louwanda. 2013. Cabin Pressure: African American Pilots, Flight Attendants, and Emotional Labor. Lanham: Rowman \& Littlefield Publishers.

Evans, Louwanda, and Wendy Leo Moore. 2015. "Impossible Burdens: White Institutions, Emotional Labor, and Micro-Resistance." Social Problems 62(3):439-54. doi: 10.1093/socpro/spv009.

Fields, Karen E., and Barbara J. Fields. 2014. Racecraft: The Soul of Inequality in American Life. Reprint Edition. London: Verso.

Garbes, Laura. 2021. "When the 'Blank Slate' Is a White One: White Institutional Isomorphism in the Birth of National Public Radio." Sociology of Race and Ethnicity 2332649221994619. doi: 10.1177/2332649221994619.

Gualtieri, Gillian. 2021. "Discriminating Palates: Evaluation and Ethnoracial Inequality in American Fine Dining." Social Problems (spaa075). doi: 10.1093/socpro/spaa075.

Hall, Stuart. 1996. "Race, Articulation, and Societies Structured in Dominance." in Black British Cultural Studies: A Reader, edited by H. A. B. Jr, M. Diawara, R. H. Lindeborg, and R. H. Lindeborg. University of Chicago Press.

Hesmondhalgh, David, and Sarah Baker. 2010. “'A Very Complicated Version of Freedom”: Conditions and Experiences of Creative Labour in Three Cultural Industries." Poetics 38(1):4-20. doi: 10.1016/j.poetic.2009.10.001.

Hill Collins, Patricia. 1986. "Learning from the Outsider Within: The Sociological Significance of Black Feminist Thought.” Social Problems 33(6):S14-32. doi: 10.2307/800672.

Hill, Jane H. 2008. The Everyday Language of White Racism. Chichester, U.K.; Malden, MA: Wiley-Blackwell.

Itzigsohn, José, and Karida Brown. 2015. "Sociology and the Theory of Double Consciousness: W. E. B. Du Bois's Phenomenology of Racialized Subjectivity." Du Bois Review: Social Science Research on Race. Retrieved February 14, 2017 (/core/journals/du-bois-reviewsocial-science-research-on-race/article/div-classtitlesociology-and-the-theory-of-doubleconsciousnessdiv/CA9531F7AD06CED567EE93DEE8DCF21C).

Itzigsohn, José, and Karida L. Brown. 2020. The Sociology of W. E. B. Du Bois: Racialized Modernity and the Global Color Line. New York: NYU Press.

Jensen, Elizabeth. 2019. “NPR's Staff Diversity Numbers, 2019.” NPR, November 19. 
Karpf, Anne. 2006. The Human Voice : How This Extraordinary Instrument Reveals Essential Clues about Who We Are. New York: Bloomsbury Pub.

Kern, Jonathan. 2008. Sound Reporting: The NPR Guide to Audio Journalism and Production. unknown edition. Chicago: University of Chicago Press.

Kumanyika, Chenjerai. n.d. "Vocal Color in Public Radio by Chenjerai Kumanyika • Longform." Longform. Retrieved November 2, 2019 (https://longform.org/posts/vocal-color-inpublic-radio).

Lagos, Danya. 2019. "Hearing Gender: Voice-Based Gender Classification Processes and Transgender Health Inequality , Hearing Gender: Voice-Based Gender Classification Processes and Transgender Health Inequality." American Sociological Review 84(5):80127. doi: $10.1177 / 0003122419872504$.

Lamont, Michèle. 2012. "Toward a Comparative Sociology of Valuation and Evaluation." Annual Review of Sociology 38(1):201-21. doi: 10.1146/annurev-soc-070308-120022.

Lena, Jennifer C. 2019. Entitled: Discriminating Tastes and the Expansion of the Arts. Princeton: Princeton University Press.

Lippi-Green, Rosina. 2012. English with an Accent: Language, Ideology and Discrimination in the United States. Routledge.

Lopez, Ian Haney. 1994. "The Social Construction of Race: Some Observations on Illusion, Fabrication, and Choice." Harvard Civil Rights-Civil Liberties Law Review. 29(1).

Loviglio, Jason. 2008. "Sound Effects: Gender, Voice and the Cultural Work of NPR." Radio Journal: International Studies in Broadcast \& Audio Media 5(2-3):67-81. doi: 10.1386/rajo.5.2-3.67 1.

Loviglio, Jason. 2013. "Public Radio in Crisis.” Pp. 34-52 in Radio’s New Wave. Routledge.

Massey, Douglas S., and Garvey Lundy. 2001. "Use of Black English and Racial Discrimination in Urban Housing Markets: New Methods and Findings." Urban Affairs Review 36(4):452-69. doi: 10.1177/10780870122184957.

McEnaney, Tom. 2019. “This American Voice.” The Oxford Handbook of Voice Studies. Retrieved August 28, 2021 (https://www.oxfordhandbooks.com/view/10.1093/oxfordhb/9780199982295.001.0001/o xfordhb-9780199982295-e-12).

National Public Radio. 2021. "Our Commitment To Diversity.” NPR, February 24.

Negus, Keith. 1999. Music Genres and Corporate Cultures. Psychology Press.

Nigatu, Heben, and Tracy Clayton. n.d. "Was That A Microaggression Or Just Tuesday?" 
Omi, Michael, and Howard Winant. 1994. Racial Formation in the United States: From the 1960s to the 1990s. 2 edition. New York: Routledge.

Pew Research. n.d. "Trends and Facts on Public Broadcasting I State of the News Media." Pew Research Center's Journalism Project. Retrieved August 28, 2021 (https://www.pewresearch.org/journalism/fact-sheet/public-broadcasting/).

Phillips, Damon J. 2013. Shaping Jazz: Cities, Labels, and the Global Emergence of an Art Form. 1st edition. Princeton, NJ: Princeton University Press.

Pickard, Victor. 2015. America's Battle for Media Democracy: The Triumph of Corporate Libertarianism and the Future of Media Reform. Cambridge University Press.

Poindexter, Paula M., Laura Smith, and Don Heider. 2003. "Race and Ethnicity in Local Television News: Framing, Story Assignments, and Source Selections." Journal of Broadcasting \& Electronic Media 47(4):524-36. doi: 10.1207/s15506878jobem4704 3.

Purnell, Thomas, William Idsardi, and John Baugh. 1999. "Perceptual and Phonetic Experiments on American English Dialect Identification.” Journal of Language and Social Psychology 18(1):10-30. doi: 10.1177/0261927X99018001002.

Puwar, Nirmal. 2004. Space Invaders: Race, Gender and Bodies Out of Place. 1st edition. Oxford : New York: Berg Publishers.

Ray, Victor. 2019. "A Theory of Racialized Organizations." American Sociological Review 84(1):26-53. doi: 10.1177/0003122418822335.

Robinson, Cedric J., and Robin D. G. Kelley. 2000. Black Marxism: The Making of the Black Radical Tradition. 2nd edition. Chapel Hill, N.C: University of North Carolina Press.

Robinson, Russell. 2008. “Perceptual Segregation.” Columbia Law Review 108.

Rosa, Jonathan, and Nelson Flores. 2017. "Unsettling Race and Language: Toward a Raciolinguistic Perspective." Language in Society 46(5):621-47. doi: 10.1017/S0047404517000562.

Saha, Anamik. 2013. “'Curry Tales': The Production of 'Race' and Ethnicity in the Cultural Industries.” Ethnicities 13(6):818-37. doi: 10.1177/1468796813487829.

Saha, Anamik. 2018. Race and the Cultural Industries. 1 edition. Malden, MA: Polity.

St Félix, Doreen. n.d. “The Twisted Power of White Voice in 'Sorry to Bother You' and 'BlacKkKlansman.'” The New Yorker. Retrieved January 14, 2021 (https://www.newyorker.com/culture/cultural-comment/the-twisted-power-of-whitevoice-in-sorry-to-bother-you-and-blackkklansman).

Stoever, Jennifer Lynn. 2015. "Fine-Tuning the Sonic Color-Line: Radio and the Acousmatic Du Bois.” Modernist Cultures 10(1):99-118. doi: 10.3366/mod.2015.0100. 
Stoever, Jennifer Lynn. 2016. The Sonic Color Line: Race and the Cultural Politics of Listening. Reprint edition. New York: NYU Press.

Velthuis, Olav. 2007. Talking Prices. Princeton University Press.

Wang Yuen, Nancy. 2016. Reel Inequality: Hollywood Actors and Racism. None edition. New Brunswick, New Jersey: Rutgers University Press.

Ward, Jane. 2008. "White Normativity: The Cultural Dimensions of Whiteness in a Racially Diverse LGBT Organization.” Sociological Perspectives 51(3):563-86. doi: 10.1525/sop.2008.51.3.563.

Wenzel, Andrea D. 2020. "Sourcing Diversity, Shifting Culture: Building 'Cultural Competence' in Public Media.” Digital Journalism 0(0):1-20. doi: 10.1080/21670811.2020.1810585.

Wingfield, Adia Harvey. 2010. "Are Some Emotions Marked 'Whites Only'? Racialized Feeling Rules in Professional Workplaces.” Social Problems 57(2):251-68. doi: 10.1525/sp.2010.57.2.251.

Zeldes, Geri Alumit, and Frederick Fico. 2005. "Race and Gender: An Analysis of Sources and Reporters in the Networks' Coverage of the 2000 Presidential Campaign." Mass Communication and Society 8(4):373-85. doi: 10.1207/s15327825mcs0804 5.

Zeldes, Geri Alumit, Frederick Fico, and Arvind Diddi. 2012. "Differences in the Way Broadcast, Cable and Public TV Reporters Used Women and Non-White Sources to Cover the 2008 Presidential Race." Mass Communication \& Society 15(6):831-51. doi: $\underline{10.1080 / 15205436.2011 .634084 .}$.

Zuberi, Tukufu, and Eduardo Bonilla-Silva. 2008. White Logic, White Methods: Racism and Methodology. Rowman \& Littlefield. 